Вестник ВГУ. Серия: Право

УДК 341

DOI https://doi.org/10.17308/vsu.proc.law.2020.3/2996

\title{
СРАВНИТЕЛЬНЫЙ АНАЛИЗ ПРАВОВОГО РЕГУЛИРОВАНИЯ УПРОЩЕНИЯ ПРОЦЕДУР ТОРГОВЛИ В РАМКАХ НАФТА, СОГЛАШЕНИЯ США-МЕКСИКА-КАНАДА И ЕАЭС
}

\section{И. А. Климова}

Московский государственный институт международных отношений

Поступила в редакцию 18 сентября 2019 г.

\begin{abstract}
Аннотация: исследуются новелль Соглашения USMCA и Таложенного кодекса ЕАЭС в части таложенных процедур упрощения торговли, проводится их сравнительный анализ между собой и положенияли Соглашения HAФTA.

Ключевые слова: упрощение процедур торговли, Соглашение USMCA, таложенные процедуры, единое окно, предварительные решения.
\end{abstract}

Abstract: new provisions of the USMCA and EEU Customs code regarding customs procedures on trade facilitation, conducts their comparative analysis with NAFTA provisions are examined.

Key words: trade facilitation, USMCA, customs procedures, single window, advance rulings.

Упрощению процедур торговли уделяется все большее внимание на международном, региональном и национальном уровнях. Соответствующие документы были приняты в рамках Всемирной таможенной организации (пересмотренная Киотская конвенция 2006 г.) и Всемирной торговой организации (Соглашение об упрощении процедур торговли, вступившее в силу в 2017 г.) $)^{1}$. Некоторые положения данных докуменm тов нашли отражение в Таможенном кодексе Евразийского экономиче을 ского союза (далее - ЕАЭС), а также в United States - Mexico - Canada Z Agreement ${ }^{2}$ (далее - Соглашение USMCA) ${ }^{3}$. Последнее было подписано 尺े 30 ноября 2018 г. на полях саммита G20 в Аргентине и призвано заменить Северо-Американское соглашение о свободной торговле (НАФТА). Парламенты США, Канады и Мексики уже ратифицировали Соглаше-

312 ние USMCA, оно вступит в силу в первый день по истечении трех месяцев с даты письменного уведомления последней страной (Канадой) о его ратификации двух других участниц (ст. 34.5 USMCA).

Процесс переговоров по Соглашению USMCA характеризовался как поиск баланса между национальными интересами государств - участниц

${ }^{1}$ См.: Antonia Eliason. The Trade Facilitation Agreement: A New Hope for the World Trade Organization // World Trade Review. 2015. № 4 (14). P. 643.

${ }^{2}$ USMCA. В Канаде его называют «CUSMA», в Мексике «T-Mec». URL: https:// www.investopedia.com/usmca-4582387

${ }^{3}$ Cм.: Rebecca Watts. NAFTA in the Time of AMLO // Around the Region. NACLAReport on Americas. Spring 2019. Vol. 51, № 1. P. 9.

(c) Климова И. А., 2020 
переговоров и их стремлением модернизировать Соглашение НАФТА, устраняя его недостатки, ставшие очевидными в эпоху глобализации ${ }^{4}$. В ходе переговоров возникли две ключевые проблемы. С одной стороны, была необходимость существенной переработки большинства статей НАФТА, а также подготовки и согласования новых положений. С другой стороны, упорное стремление США пролоббировать собственные интересы усложняло процесс поиска взаимовыгодных договоренностей ${ }^{5}$. Мексике пришлось пойти на самые существенные уступки, Канаде - на менее значительные, однако, по мнению специалистов, данные страны избежали негативного варианта развития событий - одностороннего выхода США из НАФТА ${ }^{6}$. Переговорный процесс завершился в 2018 г. подписанием итогового варианта Соглашения USMCA тремя странами-участницами.

В ходе научных дискуссий высказывается мнение о том, что данный договор может стать одним из самых прогрессивных действующих региональных торговых соглашений ${ }^{7}$. Отмечается его потенциал по повышению конкурентоспособности Северной Америки как торгового блока и принимая во внимание невозможность сосуществования различающихся экономических систем без установления единых правил их взаимодействия ${ }^{8}$. Позитивную оценку Соглашение USMCA получило и от ряда профессиональных объединений, в числе которых - американский Торгово-промышленный консультативный комитет по правам на объекты интеллектуальной собственности (ITAC), отметивший выгодность нового Соглашения для США ${ }^{9}$.

В то же время встречаются и негативные оценки Соглашения USMCA. Оно в определенной степени способствует неправильному пониманию сути свободной торговли. Идея о том, что свобода импорта, предоставляемая государством своим гражданам, должна компенсироваться соответствующими «уступками» со стороны зарубежных государств, должна лежать в основе регулируемой («управляемой»), а не свободной торговли ${ }^{10}$. Однако именно эта идея является основной в Соглашении USMCA, кото-

${ }^{4}$ См.: Gabriella Marki \& Jenna Russo. CUSLI Experts' Roundtable Report on "Canada-United States Relations - Looking Forward" // Canada-United States Law Journal, Vol. 43. Iss. 1. Art. 8. P. 297.

${ }^{5}$ См.: Яковлев П. П. От НАФТА к ЮСМКА : реформа североамериканской 313 интеграции // Рос. внешнеэкономический вестник. 2019. № 1. С. 80.

${ }^{6}$ См.: Вяхирева Н. США по итогам 2018 года и тенденции на будущее // Глобальный прогноз РСМД 2019-2024 : сборник / сост. И. Н. Тимофеев [и др.]. М., 2019. С. 53.

${ }^{7}$ См.: «Валютные» противоречия и РТС / Т. М. Алиев [и др.] // Мониторинг актуальных событий в области международной торговли. 2019. № 38. С. 5.

${ }^{8}$ См.: Gabriella Marki \& Jenna Russo. Op. cit. P. 299-300.

${ }^{9}$ Cm.: Roberta L. Horton. The USMCA Treaty: What Changes Lie Ahead for U.S. Trademark Law? // Intellectual Property \& Technology Law Journal. 2019. Vol. 31, № 1. P. 3.

${ }_{10}$ Pierre Lemieux. Is NAFTA 2.0 Better than Nothing? // Regulation. Commerce\&Trade. Winter 2018-2019. P. 15. 


\section{Вестник ВГУ. Серия: Право}

рое призвано стать модифицированным договором по свободной торговле в Северной Америке.

Что касается позиции деловых кругов в отношении Соглашения USMCA, многие представители американского бизнес-сообщества всецело поддерживали прежний договор НАФТА, однако немало сторонников было и у пересмотра данного соглашения с тем, чтобы внести в него выгодные для делового сообщества положения ${ }^{11}$.

Поскольку упрощение таможенных процедур представляет собой одну из новых областей внешнеэкономической политики государств, продиктованной, в значительно степени, интересами бизнеса ${ }^{12}$, Соглашение USMCA не могло оставить ее в стороне. Правовой базой для главы 7 Coглашения USMCA «Таможенное администрирование и упрощение процедур торговли» послужила глава 5 Соглашения НАФТА «Таможенные процедуры». Она была дополнена рядом уточняющих норм, заимствованных из Соглашения о Транстихоокеанском партнерстве (ТРP) 2018 г. и Соглашения ВТО по упрощению процедур торговли (TFA) 2013 г. ${ }^{13}$ Целью последнего было упрощение, удешевление и ускорение трансграничного движения товаров, в частности за счет уменьшения числа требуемых документов и сроков их оформления ${ }^{14}$. В главе 5 НАФТА, посвященной таможенным процедурам, особое внимание уделяется вопросам сотрудничества в сфере реализации положений таможенного законодательства, обмена информацией, стандартизации данных для упрощения процедур торговли в Северной Америке ${ }^{15}$. В целом, в результате заключения соглашения НАФТА произошла либерализация торговли между США, Мексикой и Канадой, малый и средний бизнес двух последних стран существенно пострадал, не выдержав конкуренции с крупными американскими производителями ${ }^{16}$. Нормы об упрощении процедур торговли нового Соглашения USMCA призваны поддержать небольшие и средние компании, сокращая их финансовые и временные издержки на таможен-

글 ные процедуры, таким образом, несколько выравнивая их конкурентные ○े позиции.

${ }^{11}$ Cм.: Stewart Terence P., Noorbaloochi Shahrzad. The Usmca \& United StatesCanada Trade Relations: The Perspective of a U.S. Trade Practitioner // Canada-

314 United States Law Journal. 2019. № 43. P. 281.

${ }^{12}$ См.: Сабельников Л. В. Интересы бизнеса во внешней и внешнеэкономической политике зарубежных стран // Рос. внешнеэкономический вестник. 2017. № 7. C. 87.

${ }^{13}$ См.: Воронцова Н. А. Всемирная торговая организация : к вопросу об упрощении таможенных процедур торговли. Ч. 1 // Моск. журнал междунар. права. 2018. № 1 (106). С. 44-59; Ее же. Всемирная торговая организация : к вопросу об упрощении таможенных процедур торговли. Ч. 2. // Там же. № 3. С. 53-64.

${ }^{14}$ См.: Сабельников Л. В. Указ. соч. С. 89.

${ }^{15}$ См.: Hufbauer G. C., Jeffrey J. S. NAFTA: an assessment. Washington, DC: Institute for International Economics. 1993. P. 71.

${ }^{16}$ См.: Костюнина Г. М. Североамериканская интеграция : 20 лет спустя // Вестник МГИМО-Университета. 2015. № 2. С. 235. 
Международное и европейское право

Несмотря на то что ЕАЭС и НАФТА представляют собой разные ступени интеграции - экономический союз и зона свободной торговли соответственно ${ }^{17}$, вопрос об упрощении процедур торговли актуален для обоих объединений. Среди новелл USMCA, отличающих его от НАФТА, введение самого понятия «упрощение процедур торговли» и вынесение относящихся к нему положений в отдельную главу (глава 7 USMCA «Таможенное администрирование и упрощение процедур торговли»). Кроме того, ограничены вопросы, по которым таможенными органами могут приниматься предварительные решения. Предполагается создание профильного комитета по упрощению процедур торговли. Данные изменения будут рассмотрены более подробно.

Новшеством Соглашения USMCA является также требование к странам-участницам ввести в действие или поддерживать функционирование уже существующей системы «единого окна», благодаря которой станет возможным подавать все документы и сведения, требуемые для импорта, через единую точку доступа. Таким образом, увеличится скорость выпуска товаров за счет ускорения процедуры выдачи разрешений на импорт и других разрешений контролирующих органов. При этом Соглашением предусмотрена перспектива дальнейшего расширения системы и на импортные, экспортные, и транзитные операции (ст. 7.10 «Единое окно»). Соглашение НАФТА подобной нормы не содержало - она появилась только в Соглашении об упрощении процедур торговли ВТО, однако рекомендательный характер нормы в последнем ставит под вопрос ее фрактическую реализацию.

Что касается Таможенного кодекса ЕАЭС, положений непосредственно о «едином окне» в нем нет, однако несколько статей Кодекса в совокупности можно рассматривать в качестве правовой базы для создания механизма «единого окна» в рамках ЕАЭС ${ }^{18}$. Так, в соответствии со ст. 361 кодекса при совершении таможенных операций таможенные органы собирают информацию об участниках внешнеэкономической деятельности путем ее получения от государственных органов государств-членов. ТК ЕАЭС закрепляет также возможность обмена сведениями и (или) документами в электронной форме через Интернет или посредством взаимодействия информационных систем государств (ст. 362 ТК ЕАЭС). В настоящее время создание «единых окон» идет на национальном уровне стран - членов ЕАЭС, при этом в расчет принимаются рекомендации Европейской экономической комиссии ООН и опыт Всемирной таможенной организации ${ }^{19}$. После создания пяти национальных механизмов «единого окна» планируется их интеграция между собой посредством

${ }^{17}$ См.: Анубриева Л. П. ЕАЭС и «право ЕАЭС» в международно-правовом измерении // Моск. журнал междунар. права. 2016. № 4 (104). С. 51.

${ }^{18}$ См.: Гирич М. Г., Коваль А. А. Единое окно возможностей для российских экспортеров // Рос. внешнеэкономический вестник. 2017. № 11.

${ }^{19}$ См.: Абакулов Л. Л. Перспективы внедрения и развития «единого окна» в Евразийском экономическом союзе // Вестник Курганского гос. ун-та. 2015. № 5 (39). C. 109. 


\section{Вестник ВГУ. Серия: Право}

наднациональной информационной системы ЕАЭС; в результате заинтересованные субъекты смогут получать услуги через единое окно других государств - членов Союза. На данном этапе отмечаются различия в уровнях развития «единого окна» в странах. Так, в России уже введены в действие системы электронного декларирования, «единого окна» в морском порту, межведомственного электронного взаимодействия, тогда как в Казахстане налажена работа системы электронного лицензирования, включающая в себя различные виды сертификатов, лицензий, разрешительных документов ${ }^{20}$.

В Комплексной программе развития ФТС России на период до 2020 г. в качестве одного из целевых приоритетов развития Службы является «внедрение лучших мировых практик таможенного администрирования», среди которых «электронная таможня» и механизм «единого окна».

В целях совершенствования таможенного администрирования в морских и речных портах, реализации механизма «единого окна» ФТС России разработала и внедрила «комплекс программных средств «Портал Морской порт» ${ }^{21}$, обеспечивающий информационное взаимодействие между всеми заинтересованными участниками бизнес-процессов в морских портах, а также принятие решений государственными контролирующими органами в электронной форме 22 .

Данная программа включает в себя такие элементы, как электронный документооборот, предварительное информирование и единая система управления ресурсами, объединяя представителей государственных органов (ФТС России, Роспотребнадзора, Россельхознадзора и др.) и импортеров товара, судовых агентов и т. д. Важным преимуществом программы является возможность использования ее участниками электронных документов с электронной цифровой подписью, что избавляет от

${ }^{20}$ См.: Мозер С. В., Секербаева Д. К. Перспективы развития национального механизма «единого окна» в государствах - членах ЕАЭС на современном этапе // Академический вестник Ростовского филиала Рос. таможенной академии. 2017. № 3 (28). С. 19 .

${ }^{21}$ Об утверждении Технологии совершения таможенных операций в отношении судов, используемых в целях торгового мореплавания, а также товаров и транспортных средств, перемещаемых через таможенную границу Евразийского экономического союза этими судами, с использованием Единой автоматизированной информационной системы таможенных органов и признании не подлежащим применению приказа ГТК России от 12 сентября 2001 г. № 892 «Об утверждении Положения о таможенном оформлении и таможенном контроле судов, используемых в целях торгового мореплавания, а также товаров, перемещаемых через таможенную границу Российской Федерации этими судами» : приказ ФТС России от 1 апреля 2019 г. № 541. Доступ из справ.-правовой системы «КонсультантПлюс».

22 Доклад о результатах мониторинга правоприменения в Российской Федерации за 2018 год. URL: http://www.consultant.ru/document/cons_doc_LAW_338846

${ }^{23}$ См.: Тонконог В. В., Филатова Е. В., Головань Т. В. Комплекс программных средств «Портал «Морской порт» как фрункциональный элемент механизма «единого окна» // Вестник Рос. таможенной академии. 2019. № 2. С. 56. 


\section{Международное и европейское право}

В России действует ряд административных регламентов Федеральной таможенной службы (ФТС России), регулирующих вопросы осуществления таможенного контроля товаров, перемещаемых различными видами транспорта, при ввозе в Россию либо вывозе из нее. Со ссылкой на упомянутую выше ст. 361 ТК ЕАЭС они предоставляют право должностным лицам при осуществлении таможенного контроля перемещаемых через границу товаров «осуществлять сбор информации о лицах, осуществляющих внешнеәкономическую деятельность, связанную с перемещением товаров через государственную границу Российской Федерации, либо иную деятельность в отношении товаров, находящихся под таможенным контролем (п. 1 ст. 361 ТК ЕАЭС)», а перевозчикам, в отношении которых осуществляются мероприятия по государственному контролю (надзору) право «на ознакомление с документированной информацией о себе, имеющейся у таможенных органов, и на уточнение этой информации в целях обеспечения ее полноты и достоверности, в том числе полученной таможенными органами в рамках межведомственного информационного взаимодействия от иных государственных органов, органов местного самоуправления либо подведомственных государственным органам или органам местного самоуправления организаций, в распоряжении которых находятся эти документы и (или) информация, включенные в межведомственный перечень (п. 1 ст. 361 ТК ЕАЭС, Приказы ФТС России)».

Указанные выше нормативно-правовые акты Российской Федерации составляют элементы правового регулирования элементов «единого окна».

В целом, реализация механизма «единого окна» в рамках ЕАЭС позволит облегчить доступ к сведениям об участниках ВЭД, существенно снизить временные затраты на реализацию ряда процедур, таких как обработка информации, повысить эффрективность обмена данными между государственными органами и, соответственно, существенно ускорить проведение экспортных административных процедур ${ }^{24}$.

По оценкам ОЭСР, немаловажное значение в системе упрощения процедур торговли имеют предварительные решения ${ }^{25}$. Они способствуют стабильности совершения таможенных операций, фрормированию единой практики и уменьшению числа конфликтных ситуаций ${ }^{26}$, обеспечивают импортерам и экспортерам бо́льшую уверенность относительно таможенного статуса перевозимых товаров ${ }^{27}$. Согласно положениям ст. 7.5

${ }^{24}$ См.: Гирич М. Г., Коваль А. А. Указ. соч.

${ }^{25}$ Why trade facilitation matters in today's global economy. URL: https://www. oecd.org/tad/facilitation/OECD_Trade_Facilitation_Indicators_updated-flyer_ May_2013.pdf

${ }^{26}$ См.: Халипов С. В. Правовые и практические аспекты реализации Российской Федерацией Соглашения ВТО об упрощении процедур торговли в условиях Евразийского экономического союза // Таможенное дело. 2016. № 4.

${ }^{27}$ Cм.: Hufbauer G. C., Jeffrey J. S. NAFTA: an assessment. Washington, DC: Institute for International Economics, 1993. P. 71. 


\section{Вестник ВГУ. Серия: Право}

USMCA, таможенные органы стран-участниц Соглашения принимают предварительные решения до ввоза товара на их территорию. Такие решения, согласно ст. 7.5 Соглашения, принимаются по вопросам классификации товаров, применения методов определения таможенной стоимости, происхождения товаров, отнесения товаров под тарифные квоты.

Соглашение НАФТА (раздел С, ст. 509) предусматривает более широкий круг вопросов, по которым принимаются предварительные решения (включая категории беспошлинного повторного ввоза товаров и соответствия требованиям маркировки происхождения). При этом как USMCA, так и НАФТА предоставляют право странам-участницам самостоятельно договориться и о других вопросах, по которым будут приниматься предварительные решения.

В ТК ЕАЭС содержатся также нормы относительно предварительных решений о классификации товара (ст. 24-27), происхождении товара (ст. 32-34), по вопросам применения методов определения таможенной стоимости ввозимых товаров (п. 5 ст. 359$)^{28}$. В целом, круг вопросов, по которым принимаются предварительные решения, аналогичен содержащемуся в USMCA за тем исключением, что в ТК ЕАЭС нет такой категории, как «подпадание товара под действие квот». Дальнейшее расширение круга таких вопросов входит в компетенцию Евразийской экономической комиссии.

В России принятие предварительных решений о классификации товара таможенными органами выносится на основании ст. 18 Федерального закона «О таможенном регулировании в Российской Федерации» в соответствии с упомянутыми выше ст. 23-27 ТК ЕАЭС и действует в течение пяти лет со дня его принятия. В свою очередь, согласно п. 7 ст. 7.5 USMCA, предварительное решение является бессрочным: оно сохраняет m свою силу до того, пока не будет изменено или отозвано. Бессрочный ха-

이 рактер действия предварительных решений - значительный шаг вперед, поскольку данное положение не содержится ни в Соглашении об упрощении процедур торговли ВТО, ни в Соглашении о Транстихоокеанском партнерстве, которые послужили основой рассматриваемой главы 7 $\mathrm{USMCA}^{29}$. Несмотря на то что новый Таможенный кодекс ЕАЭС позволил

318 законодателям государств-членов по собственному усмотрению увеличивать срок действия предварительного решения с трех лет со дня его принятия, зафиксированный ранее в ТК ТС, представляется, что дальней-

${ }^{28}$ См.: Туланова Н. И. Особенности применения в ЕАЭС предварительного информирования таможенных органов о товарах, перемещаемых морским транспортом // Публичные и частные интересы в условиях унификации таможенного законодательства : сб. науч. трудов Саратовского национального исследовательского гос. ун-та имени Н. Г. Чернышевского. Саратов, 2017. С. 289.

${ }^{29}$ В п. 3 ст. 3 Соглашения об упрощении процедур торговли говорится лишь о том, что «предварительное решение должно быть действительно в течение разумного периода времени после его выдачи», а п. 3 ст. 5.3 устанавливает минимальный срок действия предварительного решения в 3 года. 


\section{Международное и европейское право}

шее увеличение срока действия предварительных решений в российском законодательстве способствовало бы большей определенности и стабильности для участников ВЭД, а также позволило бы уменьшить число споров между ними и компетентными таможенными органами.

Положения Соглашения USMCA и ТК ЕАЭС несколько различаются и по срокам принятия предварительного решения таможенными органами. Согласно USMCA, такое решение «должно быть принято так быстро, насколько это возможно, и в любом случае не позднее 120 дней после получения таможенным органом всей необходимой информации от запрашивающего решение лица». В свою очередь, ТК ЕАЭС устанавливает обязанность таможенного органа принять предварительное решение о классификации товара или о происхождении товара в срок, не превышающий 90 календарных дней со дня регистрации таможенным органом заявления о принятии такого предварительного решения. При этом «законодательством государств-членов о таможенном регулировании может быть установлен менее продолжительный срок принятия предварительного решения» (ст. 25, 35 ТК ЕАЭС).

Так, п. 18 ст. 18 Федерального закона «О таможенном регулировании в Российской Федерации» предусмотрено принятие предварительного решения о классификации товара в течение 60 календарных дней со дня регистрации уполномоченным таможенным органом заявления о принятии предварительного решения о классификации товара. Таможенный кодекс ЕАЭС и российское законодательство, аналогично положениям Соглашения USMCA, учитывают возможность возникновения необходимости участниками внешнеэкономической деятельности (далее - ВЭД) дополнительной информации: так, указанный срок на принятие предварительного решения приостанавливается и возобновляется со дня регистрации уполномоченным таможенным органом поступившей дополнительной информации (п. 1 ст. 25 ТК ЕАЭС, п. 18 ст. 18 Федерального закона «О таможенном регулировании в Российской Федерации»).

Судом ЕАЭС была выработана позиция относительно критериев классификации товаров в соответствии с Товарной номенклатурой внешнеэкономической деятельности ${ }^{30}$. В качестве основного критерия выступают объективные характеристики и свойства товара, способные опре- 319 делить его предполагаемое (функциональное) значение. Последнее является дополнительным критерием классификации, если объективных характеристик и свойств товара недостаточно для определения позиции или субпозиции по Товарной номенклатуре ВЭД ${ }^{31}$.

${ }^{30}$ См.: Решение Апелляционной палаты Суда от 2 июня 2016 г. по жалобе общества с ограниченной ответственностью «Севлад»; Решение Апелляционной палаты Суда от 21 июня 2016 г. по делу по жалобе закрытого акционерного общества «Дженерал Фрейт». URL: http://courteurasian.org/page-24161

${ }^{31}$ См.: Чайка K. Л. Практика Суда ЕАЭС по таможенным спорам // Таможенное дело. 2019. № 2 . 


\section{Вестник ВГУ. Серия: Право}

В судебной практике Российской Федерации по вопросу вынесения решений (в том числе предварительных) по классификации товаров содержится несколько уточняющих положений. Во-первых, наличие ранее вынесенных предварительных решений по классификации товаров, схожих по функциям с рассматриваемым товаром, не подтверждает правомерность его классификации по тому же коду ТН ВЭД, поскольку данные решения были приняты в отношении иных товаров (тогда как в силу п. 4 ст. 23 ТК ЕАЭС предварительное решение о классификации товара принимается по каждому наименованию товара, включающему в себя определенную марку, модель, артикул и модификацию) ${ }^{32}$. Во-вторых, при рассмотрении споров относительно правильности классификации товара таможенными органами суд принимает во внимание в первую очередь его объективные характеристики и свойства, которые должны соотноситься с текстами товарных позиций и соответствующих примечаний к разделам или группам Товарной номенклатуры ВЭД³, а также, в зависимости от вида товара, помимо прочего, название товара в патенте, функцию товара ${ }^{34}$, материал его изготовления, назначение и упаковку ${ }^{35}$.

Таким образом, можно отметить, что российские арбитражные суды восприняли подход Суда ЕАЭС о критериях классификации товаров в рамках споров между таможенными органами и иными участниками ВЭД.

С точки зрения обеспечения единообразия практики и недискриминационного подхода к участникам ВЭД заслуживает внимания п. 8 ст. 7.5 Соглашения USMCA, в соответствии с которым требуется, чтобы идентичные по всем существенным признакам обстоятельства и факты толковались во всех случаях одинаковым образом в контексте принятия предварительного решения. Представляется, что аналогичное положение можно было бы внести в ст. 18 Федерального закона «О таможенном регулировании в Российской Федерации», посвященную предварительным решениям. Действующий в настоящее время Приказ ФТС России

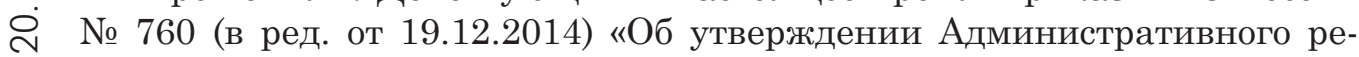
尺 гламента ФТС и определяемых ею таможенных органов по предоставлению государственной услуги по принятию предварительных решений по классификации товаров по единой Товарной номенклатуре внешне-

32 Постановление Арбитражного суда Северо-Западного округа от 30 января 2020 г. по делу № А56-75857/2018. Доступ из справ.-правовой системы «КонсультантПлюс».

${ }^{33}$ Постановление Арбитражного суда Центрального округа от 17 июля 2018 г. № Ф10-2719/2018 по делу № А62-7504/2017. Доступ из справ.-правовой системы «КонсультантПлюс».

${ }^{34}$ Постановление Тринадцатого арбитражного апелляционного суда от 1 октября 2019 г. № 13АП-24408/2019 по делу № А56-19311/2019. Доступ из справ.-правовой системы «КонсультантПлюс».

35 Постановление Девятого арбитражного апелляционного суда от 18 ноября 2019 г. № 09АП-60385/2019 по делу № А40-66246/19. Доступ из справ.-правовой системы «КонсультантПлюс». 
экономической деятельности Таможенного союза» в ст. 50.1 лишь отмечает, что при подготовке предварительного решения учитываются, среди прочего, «предварительные решения, опубликованные на официальном сайте Комиссии Таможенного союза (Евразийской экономической комиссии), и решения и разъяснения по классификации товаров ФТС России и Комиссии Таможенного союза».

Наконец, хотелось бы отметить особенности институциональных структур по соглашениям НАФТА и USMCA. Так, в рамках НАФТА была создана Комиссия по свободной торговле на уровне министров торговли стран Северо-Американской зоны свободной торговли ${ }^{36}$. По сравнению с НАФТА, в Соглашении USMCA расширен перечень трехсторонних комитетов по вопросам правил происхождения, торговли товарами, государственных закупок, перевозок, антидемпинговых мер ${ }^{37}$. В соответствии со ст. 30.1 Соглашения USMCA, сторонами-участницами также создается Комиссия по свободной торговле, однако на основании положений главы 7 USMCA создается также профильный институт - Комитет по упрощению торговли. В его функции входит, в частности, содействие обмену информацией и взаимодействию стран-участниц по вопросам создания «единого окна», программы уполномоченного экономического оператора, классификации товаров, анализа международных инициатив по упрощению процедур торговли, технической поддержки таможенных служб и др. Первая рабочая встреча Комитета должна состояться в течение одного года после вступления в силу Соглашения USMCA, последующие его заседания будут назначаться по усмотрению сторон.

Учреждение данного Комитета - один из положительных аспектов Соглашения USMCA. В целях улучшения координации взаимодействия государств - участниц ЕАЭС по вопросам упрощения процедур торговли представляется возможным создание структуры с аналогичной сферой компетенции при Коллегии Евразийской экономической комиссии (далее - ЕЭК) со статусом совещательного органа в рамках Консультативного комитета по торговле ${ }^{38}$ или в качестве самостоятельного комитета, для чего будет необходимо принятие соответствующего решения Коллегией ЕЭК.

Таким образом, новое Соглашение USMCA преобразовало некоторые устаревшие положения НАФТА в части таможенного регулирования и, в целом, создало условия для бо́льшей стабильности в экономических отношениях трех стран-участниц. Новые нормы об упрощении процедур торговли способствуют укреплению конкурентных позиций представителей малого и среднего бизнеса, которые несколько ослабли из-за преимуществ либерализации для крупных компаний.

${ }^{36}$ См.: Шепель Т. С., Мезинова И. А. Экономика, бизнес и право в новых условиях. Пенза, 2019. С. 8.

${ }^{37}$ См.: Gabriella Marki \& Jenna Russo. Op. cit. P. 299.

${ }^{38}$ Создан на основании Решения Коллегии Евразийской экономической комиссии от 7 марта 2012 г. № 6 «О Консультативном комитете по торговле». 


\section{Вестник ВГУ. Серия: Право}

Стоит также отметить прогрессивное правовое регулирование отдельных аспектов процедур упрощения торговли в Таможенном кодексе ЕАЭС. Представляется, что некоторые положения Соглашения USMCA могут послужить положительным примером для дальнейшего развития нормативной базы ЕАЭС. Среди таких норм: формирование и поддержка функционирования системы «единого окна» на всем пространстве Союза, увеличение срока действия предварительных решений в российском законодательстве (корректировка п. 2 ст. 18 Федерального закона № 289 «О таможенном регулировании в Российской Федерации и о внесении изменений в отдельные законодательные акты Российской Федерации»), включение в законодательство РФ требования о единообразном толковании компетентным таможенным органом идентичных по всем существенным признакам обстоятельств и фактов при принятии предварительного решения (дополнение ст. 18 указанного выше Федерального закона № 289), создание совещательного органа по вопросам упрощения процедур торговли при Коллегии ЕЭК. Реализация данных мер позволит существенно снизить финансовые и временные издержки участников внешнеэкономической деятельности, что будет способствовать дальнейшему развитию международной торговли.

Московский государственный институт международных отношений

Климова И. А., аспирант кафедрь международного права

E-mail: irinaklimova333@gmail.com
Moscow State University of International Relations

Klimova I. A., Post-graduate Student of the International Law Department

E-mail: irinaklimova333@gmail.com 